\title{
THE LITERATURE OF AERONAUTICS, ASTRONAUTICS, AND AIR POWER
}

Richard P. Hallion

Air Force Flight Test Center

\author{
OFFICE OF AIR FORCE HISTORY \\ UNITED STATES AIR FORCE \\ WASHINGTON, D.C. 1984
}

